\title{
X-epilectin: a novel epidermal fucolectin regulated by BMP signalling
}

\author{
KARINE MASSÉ1, REBECCA BALDWIN², MARK W. BARNETT ${ }^{3}$ AND ELIZABETH A. JONES*,1 \\ ${ }^{1}$ Molecular Physiology, Department of Biological Sciences, Warwick University, Coventry, U.K., ${ }^{2}$ Paterson Institute for Cancer Research, \\ Manchester, U.K. and ${ }^{3}$ Department of Biomedical Sciences, University of Edinburgh, Edinburgh, U.K.
}

\begin{abstract}
This paper reports the cloning and characterisation of a new posterior epidermal marker, $X$-epilectin, in Xenopus laevis. This gene encodes for a fucolectin, which belongs to the lectin superfamily of carbohydrate binding proteins and specifically binds fucose residues. RT-PCR and in situ hybridisation show that the expression of this gene is switched on during gastrulation and up-regulated during neurula stages and found expressed ubiquitously throughout the epidermis. From tailbud stages, the expression is limited to the dorsal posterior region of the embryo, suggesting that $X$-epilectin expression is regulated along anteroposterior and dorsoventral gradients during development. In the adult, $X$-epilectin is mainly expressed in intestinal components, kidney, spinal cord and skin. The effects of growth factors on the regulation of $X$-epilectin were studied. Change of the fate of animal caps into cement gland or dorsal mesoderm induces a downregulation of $X$-epilectin expression in explants treated respectively with ammonium chloride and activin $A$. We also show that $X$-epilectin expression is down-regulated by Noggin and tBR and that this effect is inhibited by BMP4 over-expression, suggesting $X$-epilectin expression is mediated by the BMP signalling pathway.
\end{abstract}

KEY WORDS: fucolectin, Xenopus laevis, epidermis, BMP signalling, anteroposterior axis

\section{Introduction}

Lectins are a diverse group of proteins, which can bind to carbohydrates. They are widely expressed and have been cloned in plants, viruses, microorganisms and animals. They are often complex, multi-domains proteins but they possess a carbohydrate-recognition domain, CRD, which recognises sugar side chains and confers the ability of these proteins to bind reversibly to specific mono- and oligo-saccharides. For example, galectins are galactoside-binding lectins whereas fucolectins (also known as anti-H-hemagglutinins) are fucose-specific binding proteins. In the animal kingdom, 5 main families have been described based on their structural CRD motif (see for review Kaltner and Gabius, 2001; Dodd and Drickamer, 2001). The C-type lectin family is the most diverse family of animal lectins and has been divided in several subgroups such as collectins and selectins. These proteins have a conserved CRD domain which recognises diverse carbohydrates such as mannose, galactose, fucose but binding to the sugar is calcium dependant. The l-type lectins have a CRD derived from the immunoglobin fold and can also bind variable carbohydrates such as hyaluronic acid or sialic acid. The con- served CRD of the galectins (or S-type lectins) recognises the $\beta$ galactosides whereas the P-type lectins bind to glycoproteins containing a mannose-6-phosphate residue. The pentraxins are the last group of the animal lectins and comprise C-reactive protein (CRP) and serum amelyoid $\mathrm{P}$ component (SAP), both major acute-phase reactants.

Because of the specificity that each lectin has towards a particular carbohydrate structure, these proteins have been used widely for blood and cell typing and for complex glycoproteins identification. Lectins, due to the high diversity of this superfamily, have been involved in many processes. The plant phytolectins were the first ones studied and are linked to host plant defense

\footnotetext{
Abbreviations used in this paper: AAA, Anguilla anguilla agglutinin; BLAST, basic local alignment search tool; BMP, bone morphogenetic protein; CRD, carbohydrate-recognition domain; EST, expressed sequence tag; I.M.AG.E, integrated molecular analysis of genomes and their expression; NCBI, National Center for Biotechnology Information; RA, retinoic acid; RT-PCR, reverse trancriptase polymerase chain reaction; $\mathrm{tBR}$, truncated BMP receptor; UTR, untranslated region; XAG-1, Xenopus anterior gradient-1.
}

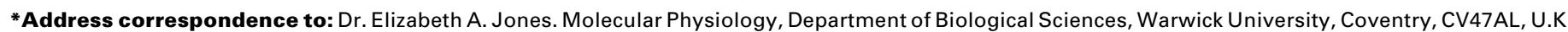
Fax: +44-24-7652-3701. e-mail: Elizabeth.Jones@warwick.ac.uk
} 
against phytogens such as fungi, insects and animals. They are involved in storage and in recognition between symbiotic nitrogen fixing bacteria. In animals, they have also been shown to play a role in host defence. In invertebrates, lectins are involved in innate direct defence and appear to act like "natural" antibodies by binding directly to pathogens and promoting phagocytosis by haemocytes. In higher animals, like mammals, collectins can also bind directly to microorganisms such as bacteria, fungi, yeast, parasites and viruses (see for review Lu et al., 2002). Collectins but also other members of the C-type lectin family are widely expressed on macrophages and are therefore involved in innate and adaptive immunity, recently reviewed by Marshall and Gordon. Moreover, the selectins are responsible for leukocyte recruitment to infection sites via extravasation and mutant mice lacking the three selectin genes show abnormally low neutrophil recruit-

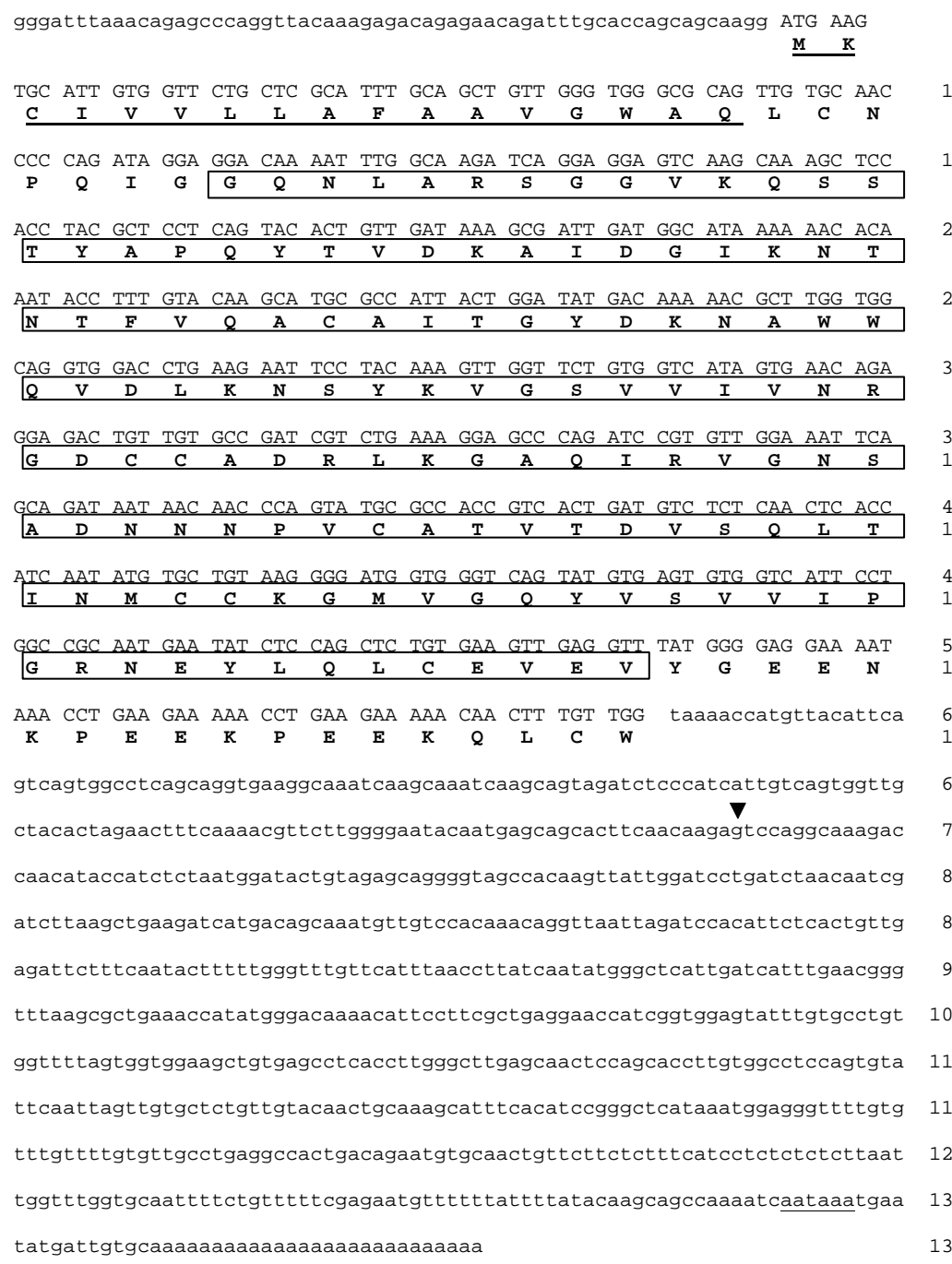

Fig. 1. Nucleotide and deduced amino acid sequence of $\boldsymbol{X}$-epilectin cDNA. The complete nucleotide sequence of X-epilectin is indicated and the deduced amino acid sequence is shown below the corresponding codon. The 5' and 3' UTR are indicated in lower case. The sequence of the eel-fucolectin tachylectin-4pentraxin-1 domain is represented in the black box. The sequence of the putative helix is underlined. The boxed area represents the polyA addition site. The black arrow indicates the $5^{\prime}$ end of the original $17 \beta$ clone. The rest of the gene sequence was obtained after analysis of the clone I.M.A.G.E. CD101366. ment (Jung and Ley, 1999). Galectins also play key roles in the immune response by, for example, modulating T-cell proliferation, death and cell adhesion (see for review, Rabinovich et al., 2002). Lectins have been shown to be involved in non-immune processes. Intracellularly, they can function in the trafficking, sorting and targeting of glycoproteins in the secretory or other thways. Moreover, lectins have been shown to regulate cell proliferation and induce mitosis but also to play a role during the development of vertebrates. Generation of galectin3 null mutant mice identified the role of this lectin in chondrocytes survival olnot et al., 2001). In Xenopus, the galactoside-binding lectin has been shown to be involved in the development of the heart but also in the formation of the melanophore pigment pattern (Frunchak and Milos, 1990; Frunchak et al., 1993).

In this paper, we report the cloning of a new member of the fucolectin family in Xenopus laevis. We also describe its spatiotemporal expression by RT-PCR and in situ hybridisation during development of Xenopus embryos and in adult frog organs. We show that this gene is specifically expressed in the larval epidermis and is excluded from the developing nervous system. On the basis of structural protein motifs and its expression domains in embryos, we have called this new gene $X$-epilectin. We show that its expression in animal caps can be modified by the treatment of animal caps with activin. We show that ammonium chloride treatment of animal caps, which induces formation of the cement gland, down regulates $X$-epilectinexpression. Finally, we investigate the role of BMP signalling in regulating the epidermal domain of $X$ epilectin expression by over-expressing the BMP antagonist Noggin and the dominant negative BMP receptor $t B R$ in animal caps to disrupt the BMP signalling pathway. Both of these treatments result in downregulation of $X$-epilectinexpression indicating a role for BMP signalling in the expression of this gene.

\section{Results}

\section{Cloning of X-epilectin}

It has been shown that formation of ectopic pronephric tubules can be induced in vitro, by treatment of animal caps with $10 \mathrm{ng} / \mathrm{ml}$ activin $A$ and $10^{-5} \mathrm{M}$ retinoic acid (RA) but not by treatment of animal caps with activin $A$ alone or RA alone (Moriya et al., 1993). We used a subtractive hybridisation approach based on this data in order to identify new molecules involved in pronephric tubules development. The subtracted probe has been already used successfully in our laboratory (Seville et al., 2002). Animal caps were cultured until stage 20 in medium containing either activin $A(10 \mathrm{ng} / \mathrm{ml})$ or $R A\left(10^{-5} \mathrm{M}\right)$ alone or a combination of these factors. cDNAs differentially induced by both factors were prepared using a suppression PCR-based subtractive hybridisation (see Materials and Methods). 
Since specification of the pronephric tubules during Xenopus laevis development occurs at stage 12.5 (Brennan et al., 1998), the subtracted probe was used to screen a stage 13 whole embryo cDNA library. Eighty-two clones were identified positive, clone $17 \beta$ was among these.

Sequence analysis revealed that $17 \beta$ was a clone of 682 nucleotides. No coding region was found in this sequence, however, a $\operatorname{Poly}(A)$ addition site and a polyA tail were found, suggesting that this clone was the 3'UTR of a gene (Fig. 1). BLAST analysis using the NCBI EST database allowed the identification of 7 overlapping clones displaying a high percentage of identity with our sequence (>98\%). One of these clones, clone BG160308, was chosen for further EST analysis as it extended furthest in the 5' direction. This new search enabled the identification of 8 new clones with greater than $97 \%$ identity to the clone BG160308 and which contained more 5' sequence. Alignment of these clones allowed us to generate the consensus sequence of this newly identified gene, $X$ epilectin. Further EST analysis failed to extend the clone further, suggesting we had identified the full-length cDNA of $X$-epilectin. The I.M.A.G.E. clone CD101366 (I.M.A.G.E. I.D.: 6938528) was chosen for analysis on the basis of the length of its 5'UTR and was ordered from the UK MRC HGMP Resource Centre, Cambridge. Sequence analysis showed that this clone contains the full length $X$-epilectin gene and that its 3 'UTR was identical to the original clone $17 \beta$. The $X$ epilectin gene (Accession number: AY689185) is $1369 \mathrm{bp}$ long and contains an open reading frame of 531 nucleotides, encoding a protein of 177 amino acids with a calculated molecular weight of $19,319 \mathrm{Da}$ (Fig. 1). The 5' UTR extends 61 bp upstream of the ATG. The termination codon is followed by 775 bp of 3' UTR, the polyA addition site (AATAAA) located 16 bp upstream of the polyA tail. Analysis of the protein sequence identifies a putative transmembrane helix, from amino acid 1 to 19 (Fig. 1). BLAST analysis on the NCBI protein databases enabled us to characterise an eelfucolectin tachylectin-4-pentraxin-1 domain (Figs. 1,2A) and to identify several related proteins containing this domain in their sequence (Fig. 2 A,B). These related proteins belong to either the Pentraxin family or to the Fucolectin family, all members of the lectin superfamily. Pentraxin proteins are acute phase reactants involved in host defences and are characterised by a specific Pentraxin/ C-reactive protein domain. In Xenopus laevis,
$A$
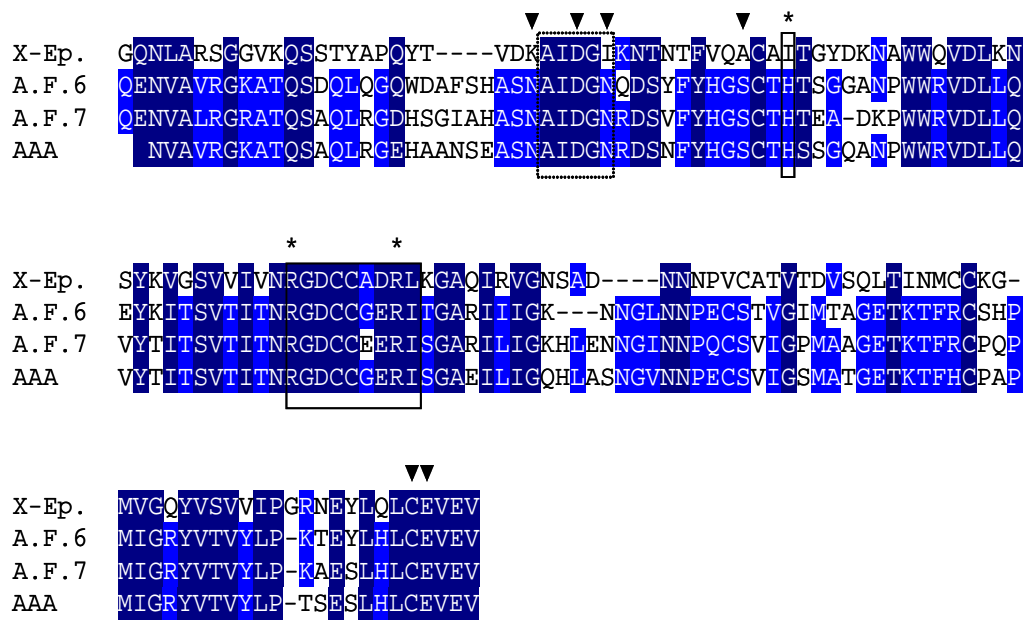

B

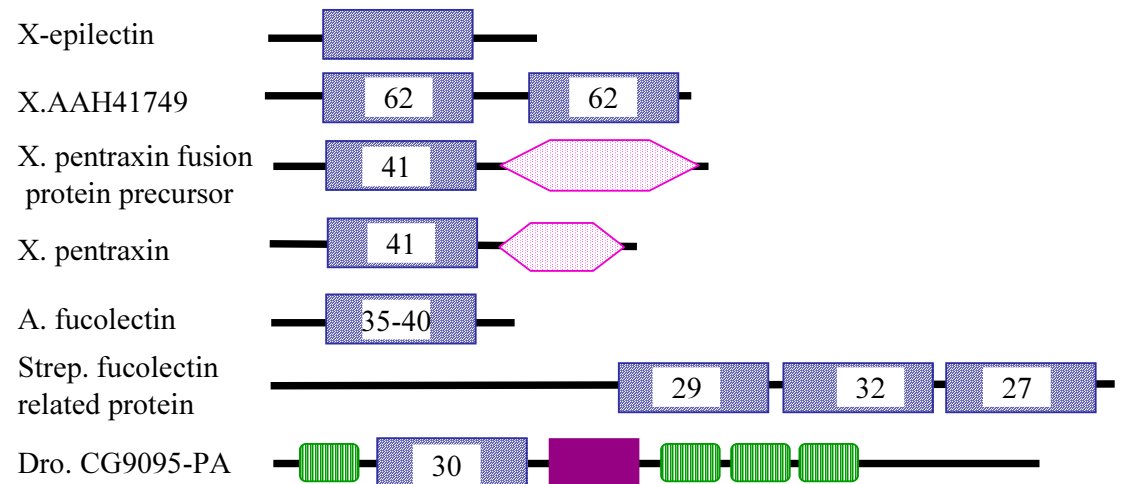

eel-Fucolectin Tachylectin-4 Pentraxin-1 Domain

Pentraxin / C-reactive protein / pentraxin family

C-type lectin (CTL) and CTL-like domains

SUSHI repeat

Fig. 2. Sequence comparison of $X$-epilectin with vertebrate lectins of similar sequence. (A) Alignment of the eel-Fucolectin Tachylectin-4 Pentraxin-1 domain of $X$-epilectin withAnguilla anguilla agglutinin and Anguilla fucolectins 6 and 7. Blast analysis shows that $X$-epilectin possesses an eelFucolectin Tachylectin-4 Pentraxin-1 domain, characteristic of Anguilla fucolectin proteins. Alignment of the fucolectin domain sequences of X-epilectin (X-ep) with Anguilla fucolectins 6 and 7 (respectively A.F.6 (BAB03528), A.F.7 (BAB03529) and Anguilla anguilla agglutinin (AAA) (Bianchet et al., 2002)) shows the high percentage of conservation of this domain (37\% identity between $X$ epilectin and AAA or fucolectin 7 to $39.7 \%$ between X-epilectin and fucolectin 6) and enables us to identify $X$-epilectin as a fucolectin protein. Conserved residues or those with the same biochemical properties (as described in Biochemistry by Lubert Stryer) are highlighted in dark blue (conserved in the 4 sequences) or pale blue (conserved in 3 sequences). The fucose-recognition motif is represented by the two black boxes, whereas the cation-binding site is represented by the dashed box (Bianchetetal., 2002). The residues participating in polar interactions with the fucose are marked with a star, residues that coordinate the cation with a triangle (Bianchet et al., 2002). (B) Motif diagram of the $X$-epilectin protein and the related known proteins containing a fucolectin domain. $A$ homology search in the NCBI databases identified several proteins in Xenopus laevis (uncloned protein AAH41749; pentraxin AAH41749 and pentraxin precursor P49263), Anguilla japonica, Streptococcus pneumonia (NP_346573) and Drosophila melanogaster (NP_573006) containing a fucolectin domain in their sequences. The percentage of identity between the fucolectin domain of $X$-epilectin and of the others proteins is also indicated. The related proteins also contain a Pentraxin domain, a C-Type lectin and CTL-like domains and a SUSHI repeat. 


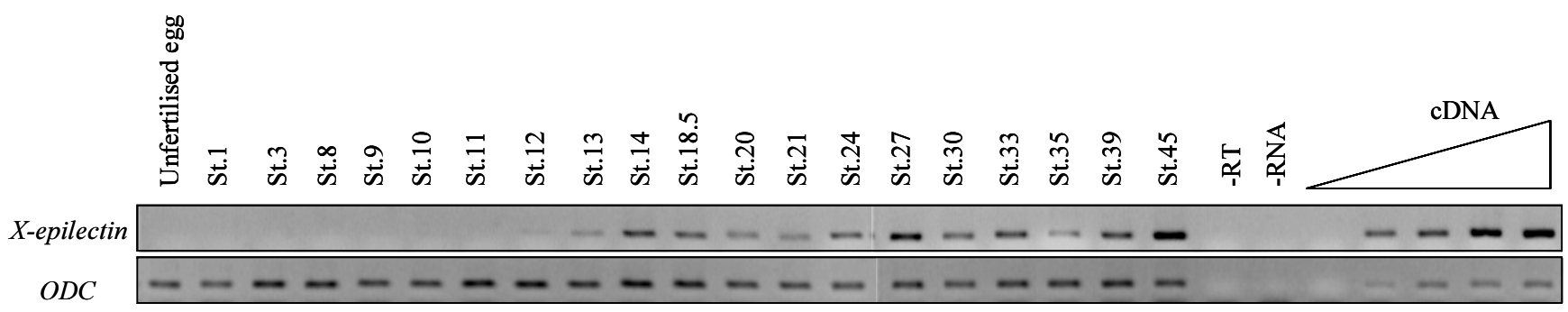

Fig. 3. Temporal expression of the $\boldsymbol{X}$-epilectin gene. RT-PCR analysis showing the expression pattern of X-epilectin transcripts in Xenopus laevis unfertilised eggs and embryos. Significant maternal expression is not detected. Zygotic expression is detected at a very low level from stage 10 and upregulated at stage 13. Expression is maintained throughout tadpole and tailbud stages. ODC was used as a loading control and cDNA from stage 45 was used for the linearity control.

several pentraxins have been cloned (Lin and Liu, 1993; Seery et al., 1993; Peavy et al., 2003) and their fucolectin domain displays $41 \%$ identity with the fucolectin domain of $X$-epilectin gene. In eel, at least 7 members of the fucolectin family have been identified (Honda et al., 2000; Bianchet et al., 2002). These proteins contain only one fucolectin domain, which is 35 to $40 \%$ identical to the fucolectin of X-epilectin. An alignment of the fucolectin domain sequence of X-epilectin with that of Anguilla fucolectins showed the highest degree of similarity of these proteins (Fig. 2A). In 2002, the crystal structure of the complex of AAA (Anguilla anguilla agglutinin) with $\alpha$-L-fucose has been solved (Bianchet et al., 2002). Residues involved in the fucose or in the cation binding have been identified. As shown in the Fig. 2A, the fucose-binding motif (His residue followed by the sequence RGDCCGER (represented by the two black boxes) is highly conserved, specially the two $\operatorname{Arg}\left({ }^{*}\right)$ which recognise the equatorial $3-\mathrm{OH}$ and $\mathrm{O} 5$ of the fucose. However, the His $\left(^{*}\right)$ involved in the recognition of the axial $4-\mathrm{OH}$ of the fucose is not present in Xepilectin sequence as is the case for Drosophila fucolectin. The binding of fucose by a fucolectin protein is calcium dependant. Three of the 6 amino acids which coordinate the cation are conserved (\%) in the X-epilectin sequence. Moreover, the motif hhDGx (marked by a dashed box), where h stands for a hydrophobic residue and $x$ for a hydrophilic residue, is present in $X$-epilectin sequence except for the $x$ residue replaced by an $h$ residue. This motif has been identified as the cation-binding site (Bianchet $e t$ al., 2002). From this alignment, we conclude therefore that $X$ epilectin codes for a fucolectin.

Interestingly, during the course of this bioinformatics analysis, an unknown protein (accession number AAH4179) was identified in Xenopus laevis, which contains two fucolectin domains, with $62 \%$ identity with the fucolectin domain of X-epilectin.

\section{Temporal expression of $\mathrm{X}$-epilectin}

The temporal expression profile of $X$-epilectin was analysed by RT-PCR (Fig. 3). No maternal expression was seen. Zygotic expression was detected at very low levels between stages 10 and 12. At stage 13, expression was up-regulated and then

A
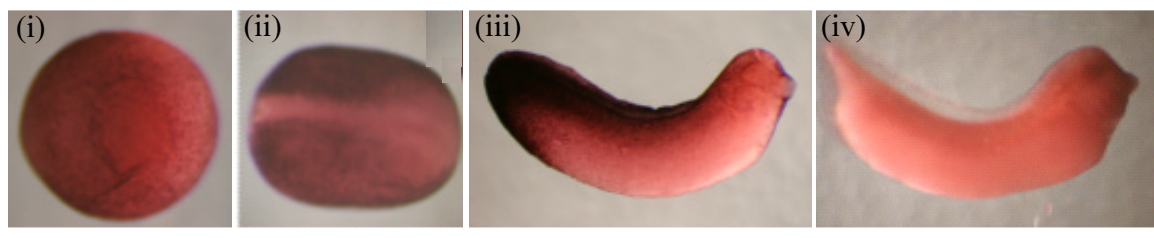

A

\section{B}
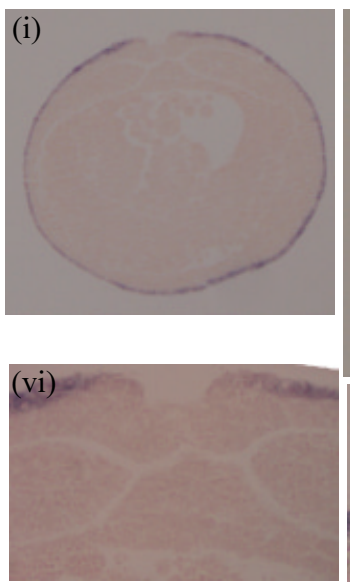
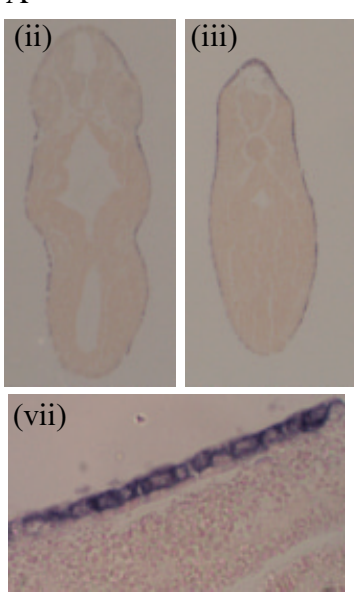

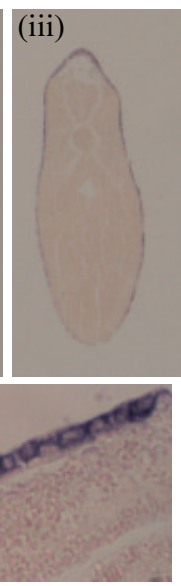

Fig. 4. Spatial expression profile of $X$-epilectin during development. (A) Wholemount in situ hybridisation with an X-epilectin DIG-labelled

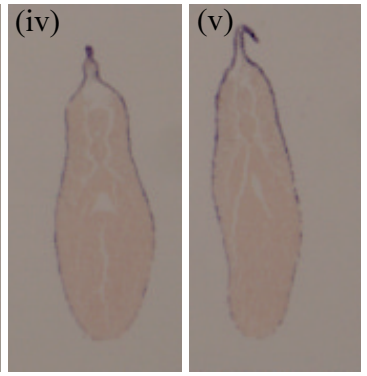
antisense RNA probe was performed on embryos from stages 10-37. No expression was detected at stage 10 (data not shown). Expression was first detected in the epidermis from stage 12 (i). At stage 16, the staining is stronger throughout the epidermis and the neural plate is totally unstained (ii). At stage 28, X-epilectin is still expressed in the epidermis but the level of its expression is higher in the posterior part of the embryo (iii). The sense probe showed no staining pattern (iv). (B) Wax sections of in situ hybridised embryos. Cross-sections through a stage 16 embryo show the ubiquitous expression of X-epilectin in the epidermis and the absence of internal staining, especially in the nervous system (i and vi). Enlargement of a crosssection through a stage 25 embryo shows that X-epilectin is mostly expressed in the outer layer of the epidermis (vii). Cross-sections through a single stage 34 embryo show the antero-posterior and dorso-ventral gradients of expression of X-epilectin (ii-v). Magnification: $x 20$ except (vi) $\times 100$ and (vii) $\times 200$ 


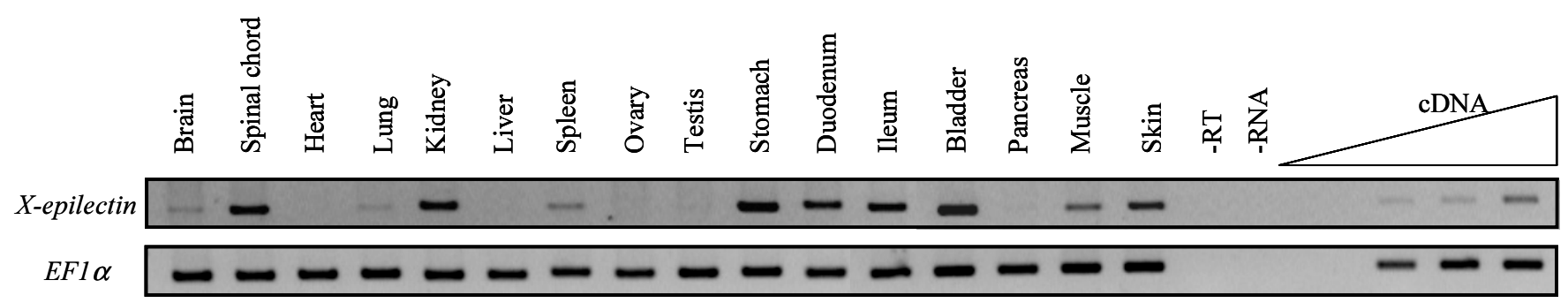

Fig. 5. Spatial expression of the $\boldsymbol{X}$-epilectin gene in the adult frog. RT-PCR analysis showing the expression pattern of X-epilectin transcripts in different Xenopus laevis adult tissues. TheX-epilectin gene is strongly expressed in intestinal tissues as well as in the kidney and in the spinal chord. EF1 $\alpha$ was used as a loading control.

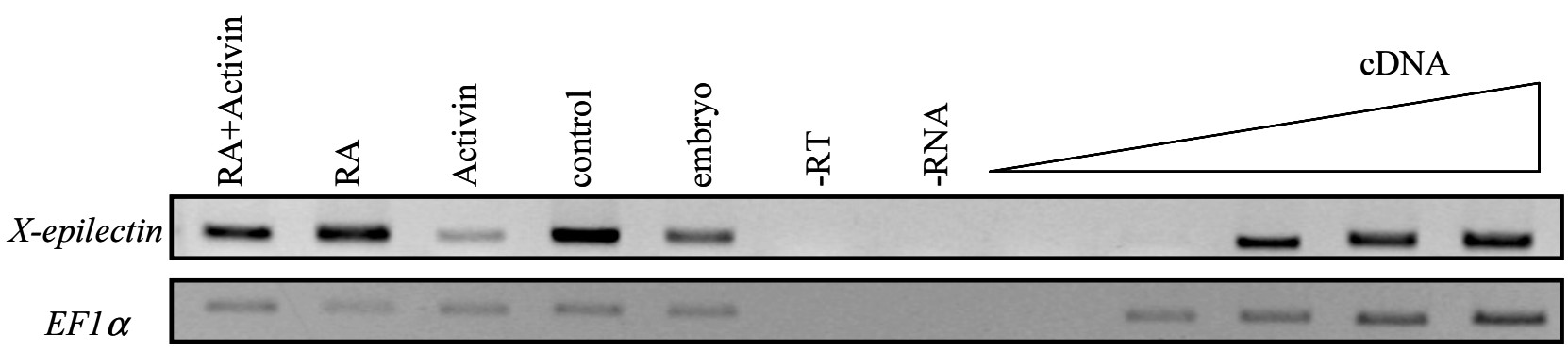

Fig. 6. X-epilectin gene expression is downregulated by Activin A. Animal caps were taken at stage 9 and cultured until stage 20 in the presence of RA+Activin A or RA alone or Activin A alone. RT-PCR analysis shows that treatment of the animal caps with Activin A alone results in a down regulation of X-epilectin expression compared to untreated caps, whereas RA treatment alone has no significant effects. Treatment of animal caps with the two treatments together decreased the effect of activin A inhibition on X-epilectin expression. EF1 $\alpha$ was used as a loading control.

maintained at the same level throughout tadpole and tailbud stages.

\section{Spatial expression of X-epilectin during Xenopus develop- ment}

The spatial expression of $X$-epilectin was analysed by in situ hybridisation in both wholemounts and wax sections (Fig. 4). No specific expression pattern can be detected at stage 10 (data not shown). Expression is first detected at stage 12 in a punctuate pattern throughout the ectoderm (Fig. 4A i). No staining was observed with the sense probe at this stage (data not shown).

During neurulation, the level of expression of $X$-epilectin in the epidermal layer increases and at stage 16, the gene is expressed ubiquitously throughout the epidermis of the embryo (Fig. 4A ii). Expression is excluded from the neural plate. During tailbud stages expression is seen evenly throughout the epidermis regardless of relative rostral position. By stage 30 , the gene is still expressed in the epidermis but its level of expression is clearly higher at the posterior end of the embryo than the anterior with no clear expression boundary (Fig. 4A iii). In addition, the expression in the dorsal epidermis extends more anteriorly that in the ventral region. $A$ sense probe showed no staining at any of the stages tested (Fig. $4 \mathrm{~A}$ iv).

In order to establish which layer/s of the epidermis were expressing $X$-epilectin, whole mount in situ stained embryos were wax embedded and sectioned at 11-micron thickness. Fig. 4B i and vii confirm the early expression pattern seen at stage 16 with expression clearly in the outer, normally pigmented, layer of the epidermis with little expression in the inner, sensorial layer. Expression is excluded from the neural groove and other internal structures such as the somites and the notochord (Fig. 4B vi). Fig.
4B ii-v show an anterior to posterior sequence of sections taken from a single stage 34 embryo. These sections clearly show decreased expression in the anterior relative to the posterior of the embryo. There also appears to be a dorsal to ventral gradient of expression with highest levels in the dorsal fin fold.

\section{Spatial expression of $\mathrm{X}$-epilectin in the adult frog}

The spatial expression of $X$-epilectin in the adult frog was assessed by RT-PCR (Fig. 5). $X$-epilectin gene is highly expressed in the intestinal components (stomach, duodenum and ileum), bladder, kidney and spinal cord. As seen in the embryo, strong expression is also found in the skin. Weak amplification is seen in the brain, lung, spleen and muscle. No expression was seen in the heart, liver, ovary, testis and pancreas.

\section{$\mathrm{X}$-epilectin is down regulated by activin $A$}

Due to the strategy of the screening, $X$-epilectin gene expression was expected to be up-regulated in animal caps by the treatment of Activin A and RA. We decided to verify if this clone was truly differential by RT-PCR (Fig. 6). Animal caps were taken at stage 9 and treated in an identical manner to those used for preparing the subtracted probe. The $X$-epilectin gene is highly expressed in control caps which form atypical epidermis as expected from the in situ hybridisation results. Treatment with Activin $A$ induces a strong downregulation of $X$-epilectin gene expression. No difference in gene expression is noticeable between RA treated animal caps and control caps, suggesting RA does not alter $X$-epilectin gene expression. However, expression of $X$-epilectin in Activin A and RA treated animal caps is slightly down regulated compared to the control caps and caps treated with RA. Therefore, RA is able to reduce the inhibitory effects of Activin A. This result could explain why this clone, 


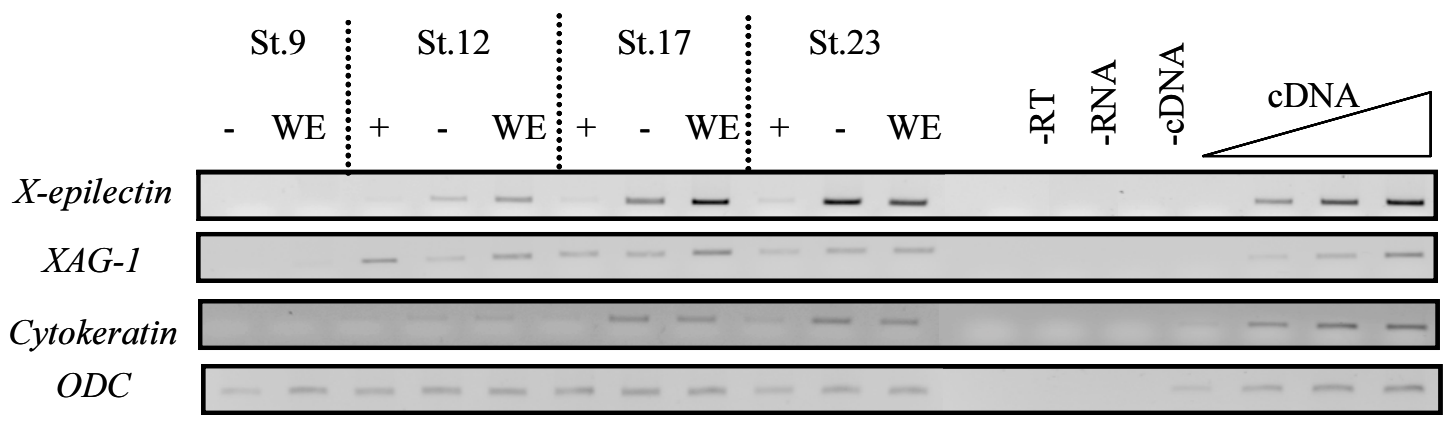

Fig. 7. $X$-epilectin expression is down regulated in animal caps treated with ammonium chloride. Animal caps were taken at stage 9 and incubated with $10 \mathrm{mM}$ ammonium chloride until stage 12 in Holfreter's solution. Control caps and treated caps were then rinsed in BarthX and cultured until desired stages. RT-PCR analysis shows a downregulation of X-epilectin expression in the treated caps, induced to form cement gland tissue. XAG-1 and cytokeratin markers were used as control. ODC was used as a loading control. +, treated with ammonium chloride; -, untreated caps; WE, whole embryo.

A

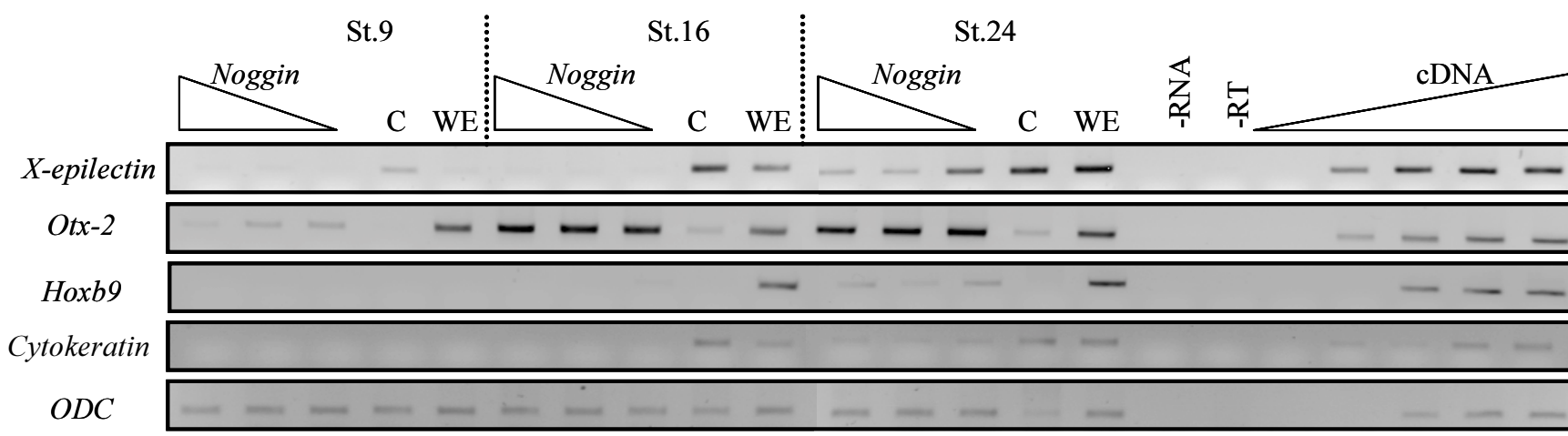

B

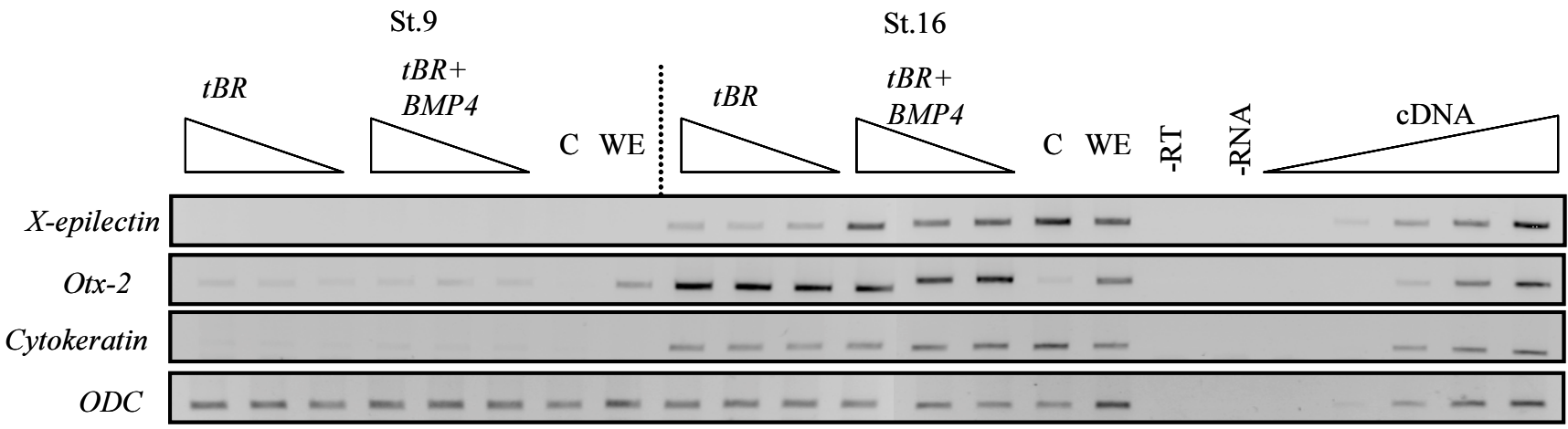

Fig. 8. $\boldsymbol{X}$-epilectin expression is down regulated by Noggin and mediated by BMP signaling. (A) One cell-stage embryos were injected with a 0.5 ng, $0.25 \mathrm{ng}$ or $0.125 \mathrm{ng}$ of Noggin mRNA. At stage 9, animal caps were taken from Noggin-injected and uninjected embryos and cultured until the desired stages. RT-PCR analysis shows microinjection of Noggin induces a downregulation of X-epilectin expression from stage 9 at least until stage 24. Otx2 and cytokeratin markers were used to control for the induction of nervous system in the animal caps. ODC was used as a loading control. (B) One cellstage embryos were injected with a $0.5 \mathrm{ng}, 0.25 \mathrm{ng}$ or $0.125 \mathrm{ng}$ of tBR mRNA. At stage 9, animal caps were taken from injected and uninjected embryos and harvested at stage 9 or at stage 16. RT-PCR analysis shows X-epilectin expression is down regulated by the overexpression of the dominant negative $B M P$ receptor. Otx-2, Hoxb9 and cytokeratin were used to control for the induction of nervous system in the tissues. ODC was used as a loading control. $C$, control caps, WE, whole embryo.

while not differential in the way we expected from the cloning strategy, came through the subtractive screen.

\section{$\mathrm{X}$-epilectin is down-regulated by ammonium chloride}

Ammonium chloride treatment has been shown to induce formation of cement gland in animal cap ectoderm (Picard, 1975) and also the expression of cement gland specific markers (Sive et al., 1989). By RT-PCR, we showed that $X$-epilectingene expression is downregulated following ammonium chloride treatment of animal caps for 7 hours (animal caps equivalent to stage 12). This downregulation is maintained until the animal caps reached stage 23 (Fig. 7). XAG-1 was used as a positive control for the induction of cement gland tissue 
and Cytokeratin for the reduction of epidermal tissue. Our results show that $X$-epilectingene expression is modulated by changing the fate of animal caps from epidermis to cement gland tissue.

\section{X-epilectin is down-regulated by Noggin, an effect which is mediated by the BMP pathway}

It has been shown that BMP4 can directly induce epidermal fate and inhibit the formation of neural tissue (Wilson and HemmatiBrivanlou, 1995). Noggin, by antagonizing BMP signalling, can induce cement gland tissue at low doses and neural tissue at higher doses (Knecht and Harland, 1997). The spatial expression of $X$-epilectin suggests that this gene could be a target for BMP signalling in Xenopus embryos. By RT-PCR analysis, we showed that expression of $X$-epilectin gene is down regulated at least until stage 24 by over-expression of a series of dilutions of Noggin mRNA in animal caps (Fig. 8A). To control the specificity of the Noggininjections Otx-2, Hoxb9and Cytokeratintranscripts were also analysed. This analysis shows that, as expected, Noggin mRNA induces anterior and not posterior, nervous system in animal cap explants. In order to establish whether this down regulation was likely to be acting through the interaction of Noggin with the BMP pathway, we have asked directly whether interference with BMP signalling can effect the same changes in $X$ epilectin expression. When animal caps are dissected from embryos over-expressing the dominant negative interfering BMP receptor, $t B R$, a similar downregulation of $X$-epilectinis observed (Fig. 8B). In animal caps over-expressing $t B R$ and $B M P 4$ the level of expression of $X$-epilectin was returned to similar levels as the uninjected animal caps. This effect is rescued by the injection of $B M P 4 \mathrm{mRNA}$, thus suggesting directly that the expression of $X$ epilectin is regulated by the BMP signalling pathway.

\section{Discussion}

\section{Characterisation of $\mathrm{X}$-epilectin}

By coupling traditional screening technique with EST database analysis, we have cloned a new gene, X-epilectin, in Xenopus laevis. Sequence analysis and conceptual translation identifies a fucolectin tachylectin-4-pentraxin-1 domain, which is homologous to Anguilla fucolectin proteins. The motifs involved in the calcium and in the fucose binding identified in AAA protein by crystallography are highly conserved in X-epilectin sequence, this suggests that this new protein is a member of the fucolectin family. Fucolectin proteins belong to the lectin superfamily of carbohydrate binding proteins and specifically bind fucose. Fucolectin proteins have been identified in bacteria (Streptococcus pneumoniae), in invertebrates and vertebrates, such as horseshoe crab (Saito et al., 1997) and Anguilla (Honda et al., 2000). Proteins with a similar domain have also been identified in insects, echinoderms and other fish species. However, even if fucosebinding lectins have also been cloned in higher vertebrates, these proteins, known under the name of collectins belong to the superfamily of C-lectins and differ to fucolectin proteins by structural properties (presence of a collagen-like domain) and their capacity to bind other residues than fucose. We speculate that the role of fucolectins in invertebrates and lower vertebrates reflects the need for a well developed innate immunity system. As adaptive immunity has evolved in higher vertebrates and assumed a greater importance, so the evolutionary pressure on fucolectins has lessened, allowing the subsequent evolution of the fucolectin gene family with a widened specificity. Our analysis allowed us to identify by similarity another uncharacterised protein in Xenopus laevis, accession number AAH41749. This protein unusually contains two fucolectin tachylectin-4-pentraxin-1 domains displaying $62 \%$ identity with the domain of $X$-epilectin. This suggests that unlike in the eel where extensive fucolectins analysis has been carried out (Honda et al., 2000), two distinct groups of fucolectin proteins are found encoded within the Xenopus genome. Lectins represent a wide group of proteins, characterised by their ability to bind specific carbohydrates. They have been cloned in plants, viruses, microorganisms and animals. In animals, five families are defined, the C-type, I-type and P-type groups, the galectins and pentraxins (Kaltner and Gabius, 2001). Several lectins have been cloned in Xenopus laevis, three pentraxins (Lin and Liu, 1993; Seery et al., 1993; Peavy et al., 2003), 12 galectins (Shoji et al., 2002 and 2003), one melibiose-binding lectin (Lee etal., 1997), two lactose-binding lectin (Marschal etal., 1992 and 1994), two serum lectins (unpublished), the oocyte cortical granule lectin (XCGL) (Nishihara et al., 1986), recently XI CGL, another member of this family of lectin, eglectin (Chang et al., 2004) and the Xenopus embryonic epidermal lectin (XEEL) (Nagata et al., 2003). The Xenopus pentraxins and the 12 galectins, like their mammalian homologs, can be classified into different groups based on their domain structures (Shoji et al., 2003). Therefore, the existence of two groups of fucolectins in the frog is not surprising, although this is the first time it has been described.

\section{$\mathrm{X}$-epilectin is specifically expressed in the skin}

This work is the first analysis of the expression of a fucolectin family member in Xenopus laevis during larval development and in the adult frog. However, the analysis of expression of the 12 galectin genes has shown that they display different spatial expression domains in the adult frog but also different temporal expression patterns during development, leading to the categorisation of these genes into three groups (Shoji et al., 2003). The expression pattern of the AAH41749 gene has not yet been investigated and therefore we are unable to determine if the two Xenopus fucolectins displayed the same expression pattern.

Our analysis has shown that $X$-epilectin is expressed in the epidermal ectoderm and is specifically excluded from the neural plate ectoderm and subsequent neural structures. $X$-epilectin is not the only lectin gene to be expressed in the larval epidermis during its development. The spatial expression of all the Xenopus lectins have not been carried out, but in situ hybridisations have been performed for X-galectin-VIla and XEEL (Shoji et al., 2003; Nagata et al., 2003). Both of these genes are also excluded from the neural plate during neurulation and expressed in the epidermis. However, at later stages, their expression patterns become very different from $X$-epilectin. Both genes remain expressed in the epidermis with the same intensity along the anterior/posterior axis of the embryo whereas $X$-epilectin expression becomes progressively restricted to the posterior end of the embryo. $X$-galectinVIIa is also expressed in the cement gland where no expression for $X$ epilectin has been detected. Two soluble lactose binding lectins, a $16 \mathrm{kDa}$ lectin and the $\mathrm{L}-14$, have been shown to be expressed in the adult Xenopusskin (Bols et al., 1986; Marschal et al., 1992 and 1994). Interestingly, the L-14 protein is not expressed during early Xenopus development (Marshal et al., 1994). 
In the adult frog, $X$-epilectin is still expressed in the skin. Our results and the published results from other Xenopus lectins, show that at least 5 lectins are expressed in the frog skin either during development or in the adult. This addresses the question of their possible physiological role in Xenopus. One possibility is that these lectins are expressed in the skin to perform some role in host defense, since Xenopus is an oviparous species, the embryos are directly exposed to pathogens. On the other hand, these molecules could have a structural role such as in cell-cell or cell-matrix interactions, as it has been suggested for the Xenopus galectin (Milos et al., 1990).

\section{Regulation of $\mathrm{X}$-epilectin expression in animal caps}

$X$-epilectin appears to be a false positive for our screening as it is not expressed in the pronephros and its expression is not upregulated in animal caps treated by $R A$ and activin. However, we show that $X$-epilectinis down-regulated by activin alone at $10 \mathrm{ng} /$ $\mathrm{ml}$, a concentration which can induce the formation of dorsal mesoderm such as notochord cells in explants. We also show that $X$-epilectin expression is down-regulated in animal caps following their treatment with $10 \mathrm{mM}$ ammonium chloride, treatment which has been shown to induce the formation of cement gland and induction of cement gland markers in animal caps (Sive et al., 1989). Therefore, the expression of $X$-epilectin is modulated by the change of the normal epidermal fate of animal caps.

During gastrulation, prospective ectodermal cells make a choice between two fates, epidermal or neural. In 1997, HemmatiBrivanlou and Melton proposed the "default model" of neuralization, with BMP4 as the epidermal inducer factor. In the absence of BMP signalling, accomplished by BMP antagonists such as Noggin or by a dominant negative BMP receptor, ectodermal cells will form neural tissue (Lamb etal., 1993; Xu etal., 1995). We show that $X$ epilectin is down-regulated in animal caps over-expressing Noggin or tBR. This downregulation is rescued by the over-expression of BMP4. Presumably the over-expression of tBR is not sufficient to dimerise with all the available molecules of binding partner. In the absence of additional BMP, endogenous level of BMP is insufficient to overcome the blockade. However, when additional BMP is added via over-expression this is sufficient to bind to the available endogenous dimerised wild type BMP receptors. These results clearly suggest that the expression of $X$-epilectin is regulated by the BMP signalling pathway.

\section{X-epilectin may be involved in epidermal development/differ- entiation}

Lectin proteins have been involved in the development of organs in vertebrates. In Xenopus laevis, modulation of the galactose-binding lectin expression alters heart and craniofacial development (Milos et al., 1993, Evanson and Milos, 1996). This protein is also involved in pattern formation of Xenopus neurites in vitro (Milos et al., 1989) and also in the distribution of the tail melanophores in vivo (Frunchak and Milos, 1990). Moreover, external fin formation can be inhibited by the exposure of trunk neural crest to an antibody raised against this galectin (Milos et al., 1993).

$X$-epilectin is expressed in the epidermis. However, contrary to the other lectins cloned in Xenopus laevis, the expression of $X$ epilectinis regulated during development. Ubiquitously expressed throughout the epidermis at neural stages, $X$-epilectin becomes more highly expressed at the dorsal posterior region of the embryo at tailbud and tadpole stages. It seems therefore that the expression of $X$-epilectin is regulated along an anteroposterior and a dorsoventral gradient, suggesting a possible role during epidermal development and/or differentiation. As far as we know, this is the first study describing an epidermal posterior marker displaying such an expression pattern. In 1999, Xepsin, an anterior epidermal marker was cloned in Xenopus laevis (Yamada et al., 1999). Its expression is limited in the anterior-dorsal region within the epidermis at tailbud stages, displaying almost the complement of the expression pattern of our gene.

\section{Anteroposterior patterning of the epidermis}

In Xenopus embryo, it has been suggested that RA forms an posterior/anterior gradient of expression (Chen et al., 1994) and it has been shown that retinoids may be involved in patterning the anteroposterior axis in the epidermis (von Bubnoff et al.,1996; Yamada et al.,1999). We show that $X$-epilectin expression is not up-regulated by RA in animal caps, suggesting that $X$-epilectin expression is not regulated by this pathway. The downregulation of $X$-epilectin expression in the anterior region of the embryo may reflect the existence of a yet uncharacterised endogenous anteriorising factor, as Xepsin expression reflects the posteriorising role of RA (Yamada etal., 1999). However, X-epilectinexpression is regulated by BMP pathway and the expression domain of $X$ epilectin overlaps with the expression of $B M P 4$ at tailbud stages (Fainsod et al., 1994; Beck and Slack, 1998). BMP signalling patterns the dorsoventral axis of the nervous system (Knecht and Harland, 1997). It has been suggested that a common mechanism for the anteroposterior axis patterning of the nervous system and the epidermis exists (Yamada et al., 1999). Therefore, it is possible that a similar common mechanism exists for the dorsoventral axis patterning of these two tissues, mediated by the BMP pathway.

\section{Materials and Methods}

\section{Preparation of the subtracted probe}

The subtracted probe was prepared as described in Seville et al., 2002. Briefly, animal caps were isolated from stage 9 Xenopus laevis embryos, by manual dissection and divided into three groups. The first group was incubated in Barth X media containing activin $A$ at $10 \mathrm{ng} / \mathrm{ml}$ and retinoic acid (RA) at $10^{-5} \mathrm{M}$. The second group was incubated in media containing activin $A$ at $10 \mathrm{ng} / \mathrm{ml}$ The third group was incubated in media containing retinoic acid at $10^{-5} \mathrm{M}$. Each group of caps was harvested at stage 20 and total RNA and then PolyA+ RNA were prepared.

The subtracted probe was prepared according the manufacturer's protocol using the PCR-Select cDNA Subtraction Kit (Clontech) with as the tester PolyA+ RNA from group one as the tester $(2 \mu \mathrm{g})$ and as the driver a pool of PolyA+ RNA from group two and three $(2 \mu \mathrm{g})$.

\section{Library screening and clone sequencing}

A stage 13 whole embryo Xenopus laevis Uni-Zap XR cDNA library was constructed and screened according to the manufacturer's protocol (Stratagene). The library was plated at a density of 50,000 plaques per plate on twenty, $150 \mathrm{~mm}$ plates and plaque lifts taken on Hybond $\mathrm{N}$ nylon filters (Amersham). Membranes were hybridised with the subtracted probe overnight at $42^{\circ} \mathrm{C}$ in $0.5 \mathrm{M}$ phosphate buffer $\mathrm{pH} 7.2$ in the presence of $7 \%$ SDS and $5 \mathrm{mM}$ EDTA. The filters were washed at room temperature in 2 X SSC, $0.1 \%$ SDS, twice at $42^{\circ} \mathrm{C}$ and then at $65^{\circ} \mathrm{C}$ in $1 \times \mathrm{SSC}, 0.1 \%$ SDS. The positive clones were purified by further rounds of screening. 
TABLE 1

\section{PRIMER SEQUENCES AND PCR CONDITIONS FOR THE REQUIRED MARKERS}

\begin{tabular}{|c|c|c|c|c|}
\hline Marker & Sequence (5'-3') & $\begin{array}{l}\text { Annealing } \\
\text { Temp }\left({ }^{\circ} \mathrm{C}\right)\end{array}$ & $\begin{array}{c}\text { No. } \\
\text { Cycles }\end{array}$ & References \\
\hline \multirow[t]{2}{*}{$X$-epilectin } & U-GGATACTGTAGAGCAGG & & & \\
\hline & D-CTCCACCGATGGTTCCT & 55 & 27 & This work \\
\hline \multirow[t]{2}{*}{ Otx-2 } & U-CATCGGACATAAAGCAGCTCATC & & & \\
\hline & D-TGCATGTTGTGATGACG & 55 & 30 & Lai et al.,1995 \\
\hline \multirow[t]{2}{*}{ Cytokeratin } & U-CATTAAGACCAGGCTGGA & & & \\
\hline & D-ATCAACCACCTCCTCGAC & 55 & 26 & Jonas et al.,1985 \\
\hline \multirow[t]{2}{*}{$X A G-1$} & U-CTGACTGTCCGATCAGAC & & & Gammill and Sive, \\
\hline & D-GAGTTGCTTCTCTGGCAT & 55 & 25 & 1997 \\
\hline \multirow[t]{2}{*}{ Hoxb9 } & U-TACTTACGGGCTTGGCTGGA & & & Hemmati-Brivanlou \\
\hline & D-AGCGTGTAACCAGTTGGCTG & 58 & 29 & and Melton, 1994 \\
\hline \multirow[t]{2}{*}{$O D C$} & U-GGAGCTGCAATTTGGAGA & & & \\
\hline & D-TCAGTTGCCAGTGTGGTC & 55 & 22 & Bassez et al., 1990 \\
\hline \multirow[t]{2}{*}{$E F 1 \alpha$} & U-CAGATTGGTGCTGGATATGC & & & \\
\hline & D-CACTGCCTTGATGACTCCTA & 55 & 19 & Mohun et al., 1989 \\
\hline
\end{tabular}

After excision of the plasmid from the positive clones, the cDNAs of interest were inserted into the phagemid pBluescript II SK (Stratagene) between the $E c o R I$ and $X h o l$ sites. The positive clones were sequenced from both strands using the BigDye Terminator Cycle Sequencing Ready Reaction Kit (Perkin-Elmer) according to the manufacturer's protocol.

\section{Sequence analysis}

Analysis of the sequences was carried out using the BLAST program (Basic Local Alignment Search Tool) (Altschul et al., 1990). Alignments were performed using the program ClustalW (Thompson et al., 1994). Conceptual translation of cDNA and analysis of the protein sequence were performed on the Infobiogen Internet site using the programs MWCALC, ScanProsite (Falquet et al., 2002) and TMpred (Hofmann and Stoffel, 1993).

\section{Embryo culture}

Embryos were obtained by in vitro fertilisation of eggs collected in Barth $X$ saline from a hormonally stimulated Xenopus laevis female by adding crushed testis isolated from a sacrificed male. Fertilised eggs were dejellied in $2 \%$ cysteine hydrochloride $\mathrm{pH} 8$ and washed several times with $1 / 10$ Barth $X$. Embryos were then cultured to the required stage in $1 / 10$ Barth $X$ in the presence of $10 \mathrm{ng} / \mathrm{ml}$ of gentamycin sulphate. The embryos were staged according to Nieuwkoop and Faber, 1994.

\section{Growth factor explant assays}

In order to analyse the differential expression of $X$-epilectin gene, animal caps were dissected in Barth $X$ using forceps and an eyebrow hair knife and cultured in Barth $X$ containing $10 \mathrm{ng} / \mathrm{ml}$ of Activin $A$ and $10^{-5} \mathrm{M}$ of RA together, Activin A alone, RA alone or no growth factor in presence of $10 \mathrm{ng} / \mathrm{ml}$ of gentamycin sulphate. At stage 20 , animal caps and control embryos were harvested and RT-PCR performed. In order to analyse the effect of ammonium chloride on $X$-epilectinexpression, animal caps were dissected as described earlier and incubated in the presence of $10 \mathrm{mM}$ ammonium chloride for 7 hours (until they reached stage 12 by reference to control whole embryos) in Holfreter's solution. Control and treated caps were rinsed in BarthX and cultured until stages 17 and 23.

\section{mRNA synthesis and microinjection}

Noggin mRNA was synthesised from Noggin/pSP64t (gift from $\mathrm{H}$. Isaacs) previously linearised with EcoRI using a mMessage mMachine kit
(Sp6 RNA polymerase, Ambion). tBR mRNA was synthesised from a plasmid previously linearised with EcoRI using the T7 mMessage mMachine kit from Ambion. O.5 ng, $0.25 \mathrm{ng}$ and $0.125 \mathrm{ng}$ mRNA of Noggin and $t B R$ was injected into dejellied embryos and placed in $6 \%$ ficoll (Sigma) in Barth $\mathrm{X}$. The following day, the embryos were transferred into $1 / 10$ Barth $X$ and cultured to the required stages.

\section{$R T-P C R$}

Total RNA from whole embryos or animal caps was isolated as described by Barnett et al., 1998. Total RNA from adult tissues was extracted using Trizol (Invitrogen) following the manufacturer's protocol. The cDNA synthesis was performed as described by Barnett et al., 1998.

Cold PCR were carried out as described in Table I. Each PCR contained-RNA, -RT and-cDNA negative controls and a linearity range to show the PCR was in the linear range. For each experiment, the quantity of input CDNA was determined by equalisation of the ODC or EF1 $\alpha$ signal.

\section{Wholemount in situ hybridisation}

Wholemount in situ hybridisation was performed as described by Harland, 1991.

Albino embryos were fixed in MEMFA (0.5M MOPS pH 7.4, $100 \mathrm{mM}$ EGTA, $1 \mathrm{mM} \mathrm{MgSO}$, 4\% formaldehyde), washed in water, dehydrated in ethanol and stored at $-20^{\circ} \mathrm{C}$. They were hybridised with either antisense or sense X- epilectin RNA probes made using a DIG RNA labelling kit (Roche). The $1.1 \mathrm{~Kb}$ fragment of the IMAGE clone CD101366, which contains the $300 \mathrm{bp}$ of the coding region and the full 3'UTR, was cloned into pBSKS. The antisense was transcribed with T7 RNA polymerase and the sense with T3 RNA polymerase from this plasmid linearised respectively by EcoRI and Sacl. The hybridisation was visualised using sheep anti-DIG-alkaline phosphatase antibody (Boehringer) and 4-nitroblue tetrazolium chloride/5-bromo-4-chloro-3-indolylphosphate substrate (NBT/ BCIP; Roche). Embryos were photographed before and after being cleared in Murrays (benzyl benzoate: benzyl alcohol 2:1), using Ektachrome160 T film (Kodak).

\section{Wax embedding and sectioning}

After overstaining wholemount in situ hybridisations, embryos were embedded in wax as described by Haldin et al., 2003. The blocks were sectioned on a microtome at $11 \mu \mathrm{m}$ thickness.

\section{Acknowledgements}

We thank S. Bhamra for technical assistance and $R$. Taylor for the maintenance of the breeding frogs. This work was supported by the BBSRC (K.M and E.A.J) and by the Wellcome Trust (M.W.B).

\section{References}

ALTSCHUL, S.F., GISH, W., MILLER, W., MYERS, E.W.and LIPMAN, D.J. (1990). Basic local alignment search tool. J Mol Biol. 215: 403-10

BARNETT, M.W., OLD, R.W.and JONES, E.A. (1998). Neural induction and patterning by fibroblast growth factor, notochord and somite tissue in Xenopus. Dev Growth Differ 40: 47-57.

BASSEZ, T., PARIS, J., OMILLI, F., DOREL, C. and OSBORNE, H.B. (1990). Posttranscriptional regulation of ornithine decarboxylase in Xenopus laevisoocytes. Development 110: 955-62.

BECK, C.W. and SLACK, J.M. (1998). Analysis of the developing Xenopustail bud reveals separate phases of gene expression during determination and outgrowth. Mech Dev. 72: 41-52.

BIANCHET, M.A., ODOM, E.W., VASTA, G.R. and AMZEL, L.M. (2002). A novel fucose recognition fold involved in innate immunity. Nat Struct Biol. 9: 628-34.

BOLS, N.C., ROBERSON, M.M., HAYWOOD-REID, P.L., CERRA, R.F. and BARONDES, S.H. (1986). Secretion of a cytoplasmic lectin from Xenopus laevis skin. J Cell Biol. 102: 492-9. 
BRENNAN, H.C, NIJJAR, S. and JONES, E.A. (1998). The specification of the pronephric tubules and duct in Xenopus laevis. Mech. Dev. 75: 127-137.

CHANG, B.Y., PEAVY, T.R., WARDRIP, N.J. and HEDRICK, J.L. (2004). The Xenopus laevis cortical granule lectin: CDNA cloning, developmental expression and identification of the eglectin family of lectins. Comp Biochem Physiol A Mol Integr Physiol. 137: 115-29.

CHEN, Y., HUANG, L. and SOLURSH, M. (1994). A concentration gradient of retinoids in the early Xenopus laevis embryo. Dev Biol. 161: 70-6.

COLNOT, C., SIDHU, S.S., BALMAIN, N. and POIRIER, F. (2001). Uncoupling of chondrocyte death and vascular invasion in mouse galectin 3 null mutant bones. Dev Biol. 229: 203-14.

DODD, R.B. and DRICKAMER, K. (2001). Lectin-like proteins in model organisms: implications for evolution of carbohydrate-binding activity. Glycobiology. 11: 71R-9R.

EVANSON, J.E. and MILOS, N.C. (1996). A monoclonal antibody against neural crest-stage Xenopus laevis lectin perturbs craniofacial development of Xenopus. J Craniofac Genet Dev Biol. 16: 74-93.

FAINSOD, A., STEINBEISSER, H. AND DE ROBERTIS, E.M. (1994). On the function of BMP-4 in patterning the marginal zone of the Xenopus embryo. EMBO J. 13: 5015-25.

FALQUET, L., PAGNI, M., BUCHER, P., HULO, N., SIGRIST, C.J, HOFMANN, K.and BAIROCH, A. (2002). The PROSITE database, its status in 2002. Nucleic Acids Res. 30: 235-238

FRUNCHAK, Y.N. and MILOS, N.C. (1990). Studies on cellular adhesion of Xenopus laevis melanophores: pigment pattern formation and alteration in vivo by endogenous galactoside-binding lectin or its sugar hapten inhibitor. Pigment Cell Res. 3: 101-14.

FRUNCHAK, Y.N., MARTHA, G.N., MCFADDEN, K.D. and MILOS, N.C. (1993). Alterations of heart development in Xenopus laevis by galactoside-binding lectin or its sugar hapten inhibitor. Anat Embryo/(Berl). 187: 299-316.

GAMMILL, L.S. and SIVE, H. (1997). Identification of otx2 target genes and restrictions in ectodermal competence during Xenopuscement gland formation. Development. 124: 471-81.

HALDIN, C.E., NIJJAR, S., MASSÉ, K., BARNETT, M.W. and JONES, E.A. (2003). Isolation and growth factor inducibility of the Xenopus laevis $\mathrm{Lm} \times 1 \mathrm{~b}$ gene. Int $J$ Dev Biol. 47: 253-62.

HARLAND, R. (1991). In situ hybridisation: an improved wholemount method for Xenopus embryos. Methods. Cell. Biol. 36: 685-695.

HEMMATI-BRIVANLOU, A. and MELTON, D.A. (1994). Inhibition of activin receptor signaling promotes neuralization in Xenopus. Cell. 77: 273-81.

HEMMATI-BRIVANLOU, A. and MELTON, D. (1997). Vertebrate embryonic cells will become nerve cells unless told otherwise. Cell. 88: 13-7.

HOFMANN, K. and STOFFEL, W. (1993). TMbase - A database of membrane spanning proteins segments. Biol. Chem. Hoppe-Seyler 374: 166

HONDA, S., KASHIWAGI, M., MIYAMOTO, K., TAKEI, Y. and HIROSE, S. (2000). Multiplicity, structures and endocrine and exocrine natures of eel fucosebinding lectins. J Biol Chem. 275: 33151-7.

JONAS, E., SARGENT, T.D. and DAWID, I.B. (1985). Epidermal keratin gene expressed in embryos of Xenopus laevis. Proc Nat/ Acad Sci USA. 82: 5413-7.

JUNG, U. and LEY, K. (1999). Mice lacking two or all three selectins demonstrate overlapping and distinct functions for each selectin. J Immunol. 162: 6755-62.

KALTNER, H. and GABIUS, H.J. (2001). Animal lectins: from initial description to elaborated structural and functional classification. Adv Exp Med Biol. 491: 79-94.

KNECHT, A.K. and HARLAND, R.M. (1997). Mechanisms of dorsal-ventral patterning in noggin-induced neural tissue. Development 124: 2477-88.

LAI, C.J., EKKER, S.C., BEACHY, P.A. and MOON, R.T. (1995). Patterning of the neural ectoderm of Xenopus laevis by the amino-terminal product of hedgehog autoproteolytic cleavage. Development. 121: 2349-60.

LAMB, T.M., KNECHT, A.K., SMITH, W.C., STACHEL, S.E., ECONOMIDES, A.N., STAHL, N., YANCOPOLOUS, G.D. and HARLAND, R.M. (1993). Neural induction by the secreted polypeptide noggin. Science. 262: 713-8.

LEE, J.K., BUCKHAULTS, P., WILKES, C., TEILHET, M., KING, M.L., MOREMEN, K.W. and PIERCE, M. (1997). Cloning and expression of a Xenopus laevis oocyte lectin and characterization of its mRNA levels during early development. Glycobiology 7: 367-72.
LIN, L. and LIU, T.Y. (1993). Isolation and characterization of C-reactive protein (CRP) cDNA and genomic DNA from Xenopus laevis. A species representing an intermediate stage in CRP evolution. J Biol Chem. 268: 6809-15.

LU, J., TEH, C., KISHORE, U. and REID, K.B. (2002). Collectins and ficolins: sugar pattern recognition molecules of the mammalian innate immune system. Biochim Biophys Acta. 1572: 387-400.

MARSCHAL, P., HERRMANN, J., LEFFLER, H., BARONDES, S.H. and COOPER, D.N. (1992). Sequence and specificity of a soluble lactose-binding lectin from Xenopus laevis skin. J Biol Chem. 267: 12942-9.

MARSCHAL, P., CANNON, V., BARONDES, S.H. and COOPER, D.N. (1994). Xenopus laevis $\mathrm{L}-14$ lectin is expressed in a typical pattern in the adult, but is absent from embryonic tissues. Glycobiology: 297-305.

MARSHALL, A.S. and GORDON, S. (2004). Commentary: C-type lectins on the macrophage cell surface - recent findings. Eur J Immunol. 34: 18-24.

MILOS, N.C., MA, Y.L. and FRUNCHAK, Y.N. (1989). Involvement of endogenous galactoside-binding lectin of Xenopus laevis in pattern formation of Xenopus neurites in vitro. Cell Differ Dev. 28: 203-9.

MILOS, N.C., MA Y.L., VARMA, P.V., BERING, M.P., MOHAMED, Z., PILARSKI, L.M. and FRUNCHAK, Y.N. (1990). Localization of endogenous galactosidebinding lectin during morphogenesis of Xenopus laevis. Anat Embryo/(Berl). 182: 319-27.

MILOS, N.C., FRUNCHAK, Y.N. and MOHAMED, Z. (1993). Probing the functions of endogenous lectins: effects of a monoclonal antibody against the neural creststage lectin of Xenopus laevis on trunk development. J Exp Zool. 266: 240-7.

MOHUN, T.J., TAYLOR, M.V., GARRETT, N. and GURDON, J.B. (1989). The CArG promoter sequence is necessary for muscle-specific transcription of the cardiac actin gene in Xenopus embryos. EMBO J. 8: 1153-61.

MORIYA, N., UCHIYAMA, H. and ASASHIMA, M. (1993). Induction of pronephric tubules by activin and retinoic acid in presumptive ectoderm of Xenopus laevis. Dev. Growth Diff. 35: 123-128.

NAGATA, S., NAKANISHI, M., NANBA, R. and FUJITA, N. (2003). Developmental expression of XEEL, a novel molecule of the Xenopus oocyte cortical granule lectin family. Dev Genes Evol. 213: 368-70.

NIEUWKOOP, P.D. and FABER, J. (1994). Normal table of Xenopus laevis (Daudin). Garland Publishing, Inc. New York.

NISHIHARA, T., WYRICK, R.E., WORKING, P.K., CHEN, Y.H. and HEDRICK, J.L. (1986). Isolation and characterization of a lectin from the cortical granules of Xenopus laevis eggs. Biochemistry. 25: 6013-20.

PEAVY, T.R., HERNANDEZ, C. and CARROLL, E.J. Jr. (2003). Jeltraxin, a frog egg jelly glycoprotein, has calcium-dependent lectin properties and is related to human serum pentraxins CRP and SAP. Biochemistry. 42: 12761-9.

PICARD, J.J. (1975). Xenopus laevis cement gland as an experimental model for embryonic differentiation. I. In vitro stimulation of differentiation by ammonium chloride. J Embryol Exp Morphol. 33: 957-67.

RABINOVICH, G.A., RUBINSTEIN, N. and TOSCANO, M.A. (2002). Role of galectins in inflammatory and immunomodulatory processes. Biochim Biophys Acta. 1572: 274-84.

SAITO, T., HATADA, M., IWANAGA, S. and KAWABATA, S. (1997). A newly identified horseshoe crab lectin with binding specificity to $O$-antigen of bacterial lipopolysaccharides. J Biol Chem. 272: 30703-8.

SEERY, L.T., SCHOENBERG, D.R., BARBAUX, S., SHARP, P.M. and WHITEHEAD, A.S. (1993). Identification of a novel member of the pentraxin family in Xenopus laevis. Proc R Soc Lond B Bio/ Sci. 253: 263-70.

SEVILLE, R.A, NIJJAR, S., BARNETT, M.W., MASSÉ, K.and JONES, E.A. (2002). Annexin IV (Xanx-4) has a functional role in the formation of pronephric tubules. Development 129: 1693-704

SHOJI, H., NISHI, N., HIRASHIMA, M. and NAKAMURA, T. (2003). Characterization of the Xenopus galectin family. Three structurally different types as in mammals and regulated expression during embryogenesis. J Biol Chem. 278: 12285-93.

SHOJI, H., NISHI, N., HIRASHIMA, M. and NAKAMURA, T. (2002). Purification and cDNA cloning of Xenopus liver galectins and their expression. Glycobiology 12: 163-72.

SIVE, H.L., HATTORI, K. and WEINTRAUB, H. (1989). Progressive determination during formation of the anteroposterior axis in Xenopus laevis. Cel/58: 171-80. 
THOMPSON, J.D., HIGGINS, D.G. and GIBSON, T.J. (1994). CLUSTALW: improving the sensitivity of progressive multiple sequence alignment through sequences weighting, position-specific gap penalties and weight matrix choice. Nucleic Acids Research 22: 4673-4680.

VON BUBNOFF, A., SCHMIDT, J.E. and KIMELMAN, D. (1996). The Xenopus laevis homeobox gene Xgbx-2 is an early marker of anteroposterior patterning in the ectoderm. Mech Dev. 54: 149-60.

WILSON, P.A. and HEMMATI-BRIVANLOU, A. (1995). Induction of epidermis and inhibition of neural fate by Bmp-4. Nature 376: 331-3.

XU, R.H., KIM,J., TAIRA, M., ZHAN, S., SREDNI, D. and KUNG, H.F. (1995). A dominant negative bone morphogenetic protein 4 receptor causes neuralization in Xenopus ectoderm. Biochem Biophys Res Commun. 212: 212-9.
YAMADA, K., TAKABATAKE, Y., TAKABATAKE, T.and TAKESHIMA, K. (1999). The early expression control of Xepsin by nonaxial and planar posteriorizing signals in Xenopus epidermis. Dev Biol. 214: 318-30.

Received: May 2004 Reviewed by Referees: July 2004 Modified by Authors and Accepted for Publication: July 2004 Edited by: Thomas D. Sargent 